\title{
Experimental Study on the Single Factor of Hydrogen Peroxide for the Degradation of Aniline
}

\author{
Yong-guang $\mathrm{Bi}^{\star}$, Min-xia Huang, Shi-ting Deng, Hong Yu, Xue-wei Chen, Xue-mei Liu , Hai-lan Huang \\ School of Pharmacy, Guangdong Pharmaceutical University, Guangzhou 510006, Guangdong, China
}

\begin{abstract}
This paper wastewater aniline reaction solution, the first reaction was added $\mathrm{H}_{2} \mathrm{O}_{2}$ degradation, changing the initial concentration of aniline were simulated wastewater, amount of $\mathrm{H}_{2} \mathrm{O}_{2}$, reaction time, $\mathrm{pH}$ value, investigate the effect of aniline degradation efficiency, the experimental results show : degradation rate of aniline in the $5.0 \mathrm{mg} / \mathrm{L}-30.0 \mathrm{mg} / \mathrm{L}$ concentration range as the initial concentration of aniline wastewater temperature increased, the $\mathrm{pH}$ value of 6:00, aniline degradation rate could reach $82.7 \%$, with the $\mathrm{H}_{2} \mathrm{O}_{2}$ increased dosage, increasing the lead degradation of aniline wastewater, and then decreased significantly, with time, the degradation rate of aniline gradually increased, reaching $79.2 \%$ in $40 \mathrm{~min}$ time.
\end{abstract}

Aniline is one of the substances most representative of aromatic amines, is a colorless, oily liquid with a fragrant odor ${ }^{[1]}$. Aniline as an important organic chemical raw materials and chemical products, widely used pesticides, printing and dyeing, military and other rubber industries. Aniline dyeing industry is one of the most important intermediates in the dye industry can be used in the manufacture of various organic dyes; in the pesticide industry, aniline is used to produce a variety of insecticides, fungicides ${ }^{[2]}$; also be used as medicine NZ acid It can be used as explosives stabilizer, gasoline proof rubber antioxidant agents, accelerators, etc.;; also the production of plastics, varnishes, perfumes, film material and other intermediates aniline, sulfa drugs ${ }^{[3,4]}$. Aniline wastewater generated in the process of industrial applications in a wide source of water large, heavy damage, its concentration from several hundred to several thousand $\mathrm{mg} / \mathrm{L}$ range, far exceeded the capacity of the environment.

Aniline is an important organic chemical raw materials and chemical products obtained by chemical products and intermediates there are nearly 300 species $^{[5,6]}$. Mainly used in dyes, pharmaceuticals, pesticides and other industries, and widely exists in these industries wastewater, with the development of chemical industry, aniline demand a clear upward trend, whereby the amount of aniline wastewater into the environment will be more more harmful to the environment is also growing, because of its highly toxic to humans and other animals and plants, the country's strict emission control standards aniline.

Aniline is a serious environmental pollution and hazardous substances harmful to human health, is a "three letter" material. Aniline is highly fat-soluble, and its vapor can rapidly through inhalation, the blood hemoglobin becomes methemoglobin and lose the ability to carry oxygen, causing the body of oxygen and suppress the central nervous system ${ }^{[7,8]}$. Initially presented symptoms of acute swelling of the nerve cells, and then dissolve the chromosome, vacuolization and cell rupture, serious cases death. There are three main pathways: ingestion, inhalation, skin absorption. Because of aniline ecological virulent organisms, has been included in the "Chinese environmental priority pollutants blacklist", it is in an industrial drainage strict requirements.
From theory, a variety of chemical and physical methods can be used in biological degradation of aniline wastewater treatment: adsorption, extraction, membrane separation, ultrafiltration, chemical oxidation, photo-oxidation, electrochemical oxidation, ultrasonic technology and biological degradation treatment method $^{[9,10]}$. But taking into account the efficiency and cost industry, the most commonly used methods are coagulation, adsorption, chemical oxidation, electrochemical oxidation. A variety of aerobic and anaerobic biological wastewater treatment technology also obtain the corresponding aniline initial results. Wastewater treatment technology at home and abroad according to the principle adopted can be summarized as physical chemistry, chemical oxidation, biodegradation, catalytic oxidation method and microwave method. Aniline coking wastewater pollutants are typically polar organic pollutants, and it has a greater toxicity ${ }^{[11]}$. Aniline, for example, which can high-speed rail red blood albumin, hemolytic anemia and liver and kidney damage. Aniline pollutants also generally has a strong carcinogenic, mutagenic effects, environmental emissions on the environment containing water pollutants aniline coking wastewater pose potential environmental risks.

This thesis paper aniline wastewater reaction solution, to join $\mathrm{H}_{2} \mathrm{O}_{2}$ degradation reactions were changing the initial concentration of aniline wastewater, adding the amount of $\mathrm{H}_{2} \mathrm{O}_{2}$, reaction time, $\mathrm{pH}$ value, investigate the effect of aniline degradation efficiency, with a view to the process applications provide a reference.

\section{Experimental Materials and Methods}

\subsection{Materials and reagents}

Aniline, potassium bisulfate, dried over anhydrous sodium carbonate, sodium nitrite, ammonium sulfamate and sulfuric acid, these reagents were of analytical reagent grade. 


\subsection{Instruments and equipment}

V1101UV/Vis spectrophotometer (Shanghai Techcomp Instrument Co.,Ltd.); AY120 electronic analytical balance (Shimadzu Corporation, Japan); KH-400KDB type CNC high-power ultrasonic cleaner (the Kunshan Hechuang Ultrasonic Instrument Co., Ltd.).

\section{Results And Discussion}

Aniline wastewater reaction solution, the first reaction was added $\mathrm{H}_{2} \mathrm{O}_{2}$ degradation, changing the initial concentration of aniline were simulated wastewater, amount of $\mathrm{H}_{2} \mathrm{O}_{2}$, reaction time, $\mathrm{pH}$ value, investigate the effect of aniline degradation efficiency, determine the role of $\mathrm{H} 2 \mathrm{O} 2$ alone most excellent condition.

\subsection{Examine the impact of the initial concentration of aniline degradation rate}

The initial concentration of the preparation of aniline were $5.0 \mathrm{mg} / \mathrm{L}, 10.0 \mathrm{mg} / \mathrm{L}, 15.0 \mathrm{mg} / \mathrm{L}, 20.0 \mathrm{mg} / \mathrm{L}$, $25.0 \mathrm{mg} / \mathrm{L}, 30.0 \mathrm{mg} / \mathrm{L}$ of simulated wastewater aniline each $30 \mathrm{~mL}$, initial $\mathrm{pH} 6.0, \mathrm{H}_{2} \mathrm{O}_{2}$ is added the amount of $0.2 \mathrm{~mL}$, reaction temperature is room temperature (about $18^{\circ} \mathrm{C}$ ), reaction time is $30 \mathrm{~min}, \mathrm{H}_{2} \mathrm{O}_{2}$ alone aniline degradation under different initial concentrations (Figure 1).

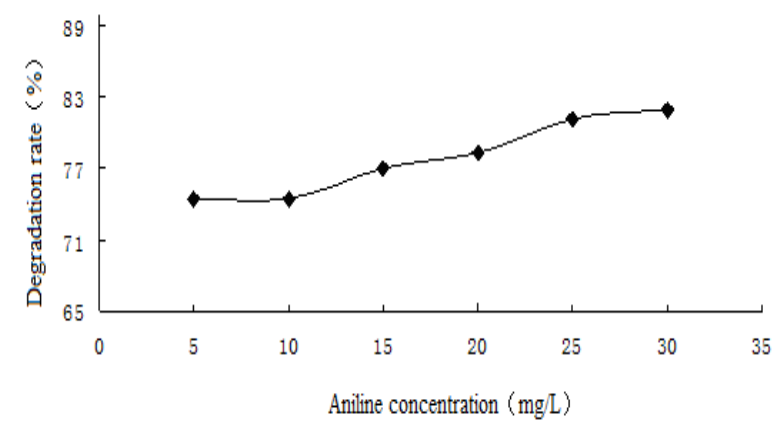

Fig.1 Effect of concentration aniline degradation rate

From Figure 1, the degradation rate of aniline in the $5.0 \mathrm{mg} / \mathrm{L}-30.0 \mathrm{mg} / \mathrm{L}$ concentration range as the initial concentration of aniline wastewater temperature increased, that is beneficial to the degradation of the higher initial concentration, lower initial concentration instead degradation rate, but with aniline concentration, increased degradation rate more slowly. Aniline concentration increases, under certain conditions, the probability of aniline in contact with reactive free radicals increases, increasing the chance to attack $\cdot \mathrm{OH}$, and in the same time to speed up the reaction rate, increased degradation rate; aniline initial concentration continued to increase, in some hydrogen peroxide under the influence of the amount received hydrogen peroxide, degradation rate increased more slowly and closer to flat. From the point of view in favor of the degradation rate, it should select a higher initial concentrations of the test.

\subsection{Effect of $\mathrm{pH}$ on the study of the degradation rate of aniline}

Preparation of initial concentration of 30.0mg / $\mathrm{L}$ of aniline wastewater 6 parts, each $30 \mathrm{~mL}, \mathrm{H}_{2} \mathrm{O}_{2}$ added in an amount of $0.2 \mathrm{~mL}$, reaction temperature is room temperature (about $18{ }^{\circ} \mathrm{C}$ ), reaction time was $30 \mathrm{~min}$, investigated the $\mathrm{pH}$ value of 2,4, $\mathrm{H}_{2} \mathrm{O}_{2}$ 6,8,10,12 alone for aniline degradation effect, shown in Figure 2.

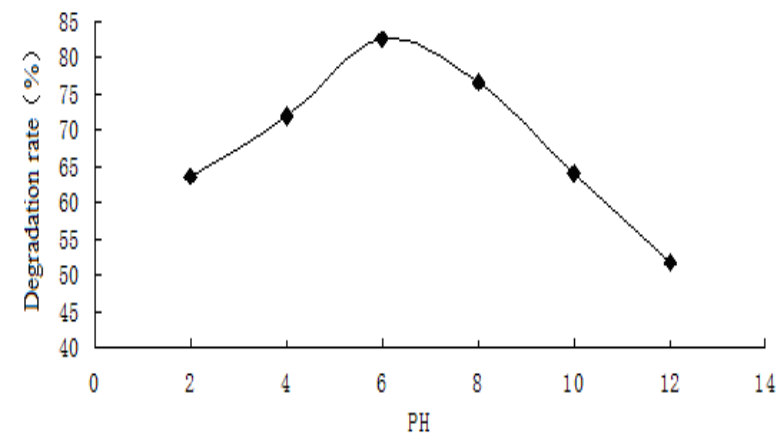

Fig.2 Effect of aniline degradation rate of the $\mathrm{pH}$ value

As it can be seen from Figure 2, when the solution is weakly acidic, the degradation rate is higher, indicating a weak acid environment can promote degradation of aniline. Solution $\mathrm{pH}$ 6, the degradation rate could reach $82.7 \%$ of aniline. Analysis, hydrogen peroxide slightly acidic, unstable in alkaline solution, may decompose to generate oxygen and water loss of oxidative capacity , in addition to when the high $\mathrm{pH}$, the solution increased $\mathrm{HCO}_{3}$ - and $\mathrm{CO}_{3}{ }^{2-}$, both are $\cdot \mathrm{OH}$ scavenger, consume free radicals, degradation rate decreased, when the $\mathrm{pH}$ value is too low, the solution is $\mathrm{H}^{+} \cdot \mathrm{OH}$ scavenger, aniline weakly alkaline, under weakly acidic conditions ionic form, in favor and $\cdot \mathrm{OH}$ reaction, the degradation rate is high. Therefore, in the experiment should be kept slightly acidic solution is more conducive to the degradation of aniline.

\subsection{Effect of aniline degradation rate study $\mathrm{H}_{2} \mathrm{O}_{2}$ dosage}

Preparation of initial concentration of $30.0 \mathrm{mg} / \mathrm{L}$ of aniline wastewater 6 parts, each $30 \mathrm{~mL}, \mathrm{pH}=6.0$, reaction temperature is room temperature (about $18^{\circ} \mathrm{C}$ ), reaction time was $30 \mathrm{~min}$, study $\mathrm{H}_{2} \mathrm{O}_{2}$ dosage $0.1 \mathrm{~mL}, 0.2 \mathrm{~mL}, 0.3$ $\mathrm{mL}, 0.4 \mathrm{~mL}, 0.5 \mathrm{~mL}, 0.6 \mathrm{~mL}$ impact on individual $\mathrm{H} 2 \mathrm{O} 2$ degradation of aniline, shown in Figure 3.

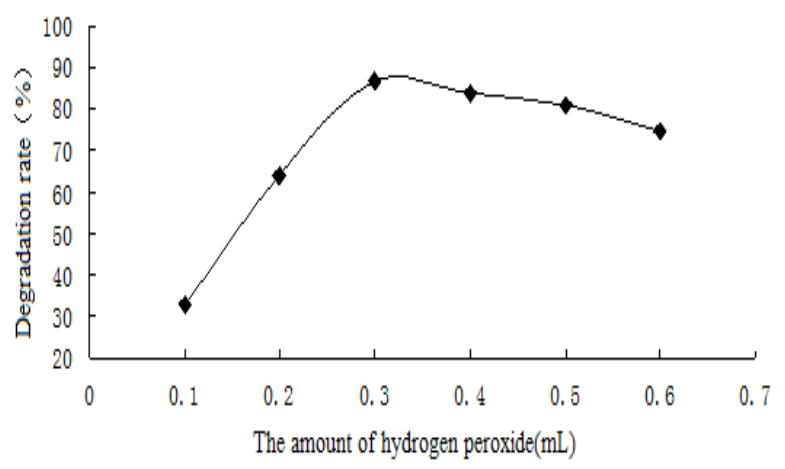

Fig. $3 \mathrm{H}_{2} \mathrm{O}_{2}$ addition on the degradation rate of aniline 
From Figure 3, with the increase of $\mathrm{H}_{2} \mathrm{O}_{2}$ dosage, wastewater aniline degradation increases the lead and then decreased significantly. When the dosage of $0.3 \mathrm{~mL}$ $\mathrm{H}_{2} \mathrm{O}_{2}$, the degradation rate of aniline maximum 86.8 percent. $\mathrm{H}_{2} \mathrm{O}_{2}$ dosage have a crucial impact on the wastewater treatment effect: At low $\mathrm{H}_{2} \mathrm{O}_{2}$ concentration, the amount of $-\mathrm{OH}$ with the increase of $\mathrm{H}_{2} \mathrm{O}_{2}$ dosage increases, and thus the degradation rate increases; but with the dosage of $\mathrm{H}_{2} \mathrm{O}_{2}$ after reaching a certain level, aniline degradation rate of decline, it is because when $\mathrm{H}_{2} \mathrm{O}_{2}$ dosage is too high, the excess through the decomposition of $\mathrm{H}_{2} \mathrm{O}_{2}$ will not be able to produce more $\bullet$ $\mathrm{OH}$ radicals, but also a decomposition reaction, and finally to the degradation rate of aniline decline.

\subsection{Examine reaction time on the degradation rate of aniline}

Preparation of initial concentration of $30.0 \mathrm{mg} / \mathrm{L}$ of aniline wastewater 6 parts, each $30 \mathrm{~mL}, \mathrm{pH}=6.0$, reaction temperature is room temperature (about $18{ }^{\circ} \mathrm{C}$ ), $\mathrm{H}_{2} \mathrm{O}_{2}$ amount of $0.2 \mathrm{~mL}$, of reaction time $10 \mathrm{~min}, 20 \mathrm{~min}, 30 \mathrm{~min}$, 40min, 50min, 60min $\mathrm{H}_{2} \mathrm{O}_{2}$ degradation of aniline alone affect the results, as shown in Figure 4.

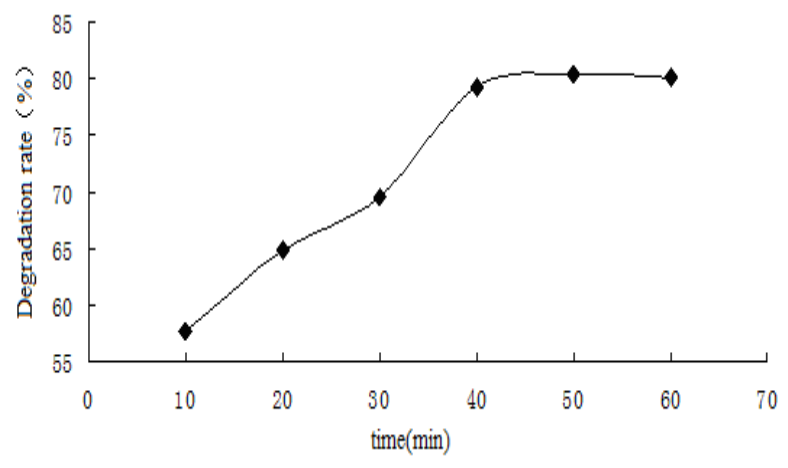

Fig.4 Reaction time on the degradation rate of aniline

(Figure 4) can be seen from the results of aniline degradation, over time, the degradation rate of aniline gradually increased, reaching $79.2 \%$ in $40 \mathrm{~min}$ time. Additional reaction time, increase was not obvious, the degradation rate of aniline degradation rate leveled off, indicating that the oxidation reaction is close to equilibrium, continue to extend the reaction time has no effect on the equilibrium. According to the theory of radical reaction, hydrogen peroxide decomposition $\bullet \mathrm{OH}$ radicals and $\bullet \mathrm{H}$ radical, an appropriate extension of time, a lot of very lively $\cdot \mathrm{OH}$ radical oxidation of the organic matter in water completely into $\mathrm{CO}_{2}$ and $\mathrm{H}_{2} \mathrm{O}$. With time, radical or charged ions in water decreases, so the degradation rate of growth gradually slowed until it stops.

\section{Conclusions}

By exploring the impact of aniline initial concentration, $\mathrm{pH}$ value, $\mathrm{H}_{2} \mathrm{O}_{2}$ dosage, reaction time and other factors on the degradation rate of aniline, experimental results show that: the degradation rate of aniline in the concentration range of $5.0 \mathrm{mg} / \mathrm{L}-30.0 \mathrm{mg} / \mathrm{L}$ with the the initial concentration of aniline wastewater temperature increased, the $\mathrm{pH}$ value of 6:00, aniline degradation rate could reach 82.7 percent, with the increase of $\mathrm{H}_{2} \mathrm{O}_{2}$ dosage, wastewater aniline degradation increases the lead and then decreased significantly, with time, the degradation rate of aniline gradually increased, reaching $79.2 \%$ at the time of 40min.

\section{Acknowledgements}

This work is supported by Guangdong Department of Water Resources Science and Technology Innovation Project (No. 2015-20).

\section{References}

[1] Emtiazi G, Satarii M, Mazaherion F. The utilization of aniline, chlorinated aniline and anilineblue as the only source of nitrogen by fungi in water[J]. Water Research, 2001, 35(5): 1219-1224.

[2] Liu B T, Yang Y, Zhang L. Experimental studies on the treatment of aniline wastewater by activated carbon fiber[J]. Advanced Materials Research, 2011, 282(7): 64-67.

[3] Datta S, Bhattacharya P K, Verma N. Removal of aniline from aqueous solution in a mixed flow reactor using emulsion liquid membrane[J]. Journal of Membrane Science, 2003, 226(1): 185-201.

[4] Kikyl G. M.. Complete physico-chemical treatment for coke plant effluents[J]. Water Research, 2002, 36(5): 1127-1134.

[5] Santos A., Yustos P., Quintanilla A., et al. Evolution of toxicity upon wet catalyticoxidation of phenol[J]. Environ. Sci. Technol., 2004, 38(1): 133-138.

[6] Strniste G., Martinez E., Martinez A. M., et al. Photoinduced reactions of benzo(a)pyrene with DNA in vitro[J]. Cancer Res., 1980, 40: 245-252.

[7] Shi H. P., Shan B. R.. A case with acute sulfureted hydrogen poisoning treated by methylene blue[J]. Zhong Hua Lao Dong Wei Sheng Zhi Ye Bing Za Zhi, 2011, 29(5):398-394.

[8] Couturier Y., Barbotin M., Bobin P., et al. Cases of toxic lung caused by ammonia vapors and sulfureted hydrogen[J]. Bull Soc. Med. Afr. Noire Lang Fr., 1971, 16(2): 250-257.

[9] Redman A., Santore R.. Bioavailability of cyanide and metal-cyanide mixtures to aquaticlife[J]. Environ. Toxicol. Chem., 2012, 16(2): 251-258.

[10] Pandolfo T. J., Cope W. G., Young G. B., et al. Acute effects of road salts and associatedcyanide compounds on the early life stages of the unionid mussel Villosa iris[J]. Environ.Toxicol. Chem., 2012, 16(2): 276-283.

[11]Belani K. G., Singh H., Beebe D. S., et al. Cyanide toxicity in juvenile pigs and its reversal by a new prodrug, sulfanegen sodium[J]. Anesth. Analg., 2012, 114(5):956-61.

[12] Yong-guang $\mathrm{Bi}$, Min-xia. Huang. Analysis degradation effect of aniline wastewater by ultrasound[J]. Advanced Materials Research, 2013, (773):923-926. 